OPEN ACCESS

Edited by:

Alexandra Papadopoulou, First Pediatric Clinic of the University of Athens, Children's Hospital Hagia

Sophia, Greece

Reviewed by:

Duška Tješić-Drinković, University of Zagreb, Croatia

Matthew Wyatt Carroll, University of Alberta, Canada

*Correspondence:

Olle Hernell olle.hernell@umu.se

Specialty section This article was submitted to Pediatric Gastroenterology, Hepatology and Nutrition,

a section of the journal

Frontiers in Pediatrics

Received: 04 June 2019 Accepted: 05 August 2019 Published: 21 August 2019

Citation:

Li X, Peng Y, Li Z, Christensen B, Heckmann $A B$, Stenlund $H$,

Lönnerdal B and Hernell O (2019) Feeding Infants Formula With Probiotics or Milk Fat Globule Membrane: A Double-Blind, Randomized Controlled Trial. Front. Pediatr. 7:347. doi: 10.3389/fped.2019.00347

\section{Feeding Infants Formula With Probiotics or Milk Fat Globule Membrane: A Double-Blind, Randomized Controlled Trial}

\author{
Xiaonan Li ${ }^{1}$, Yongmei Peng ${ }^{2}$, Zailing Li ${ }^{3}$, Britt Christensen ${ }^{4}$, Anne B. Heckmann ${ }^{5}$, \\ Hans Stenlund ${ }^{6}$, Bo Lönnerdal ${ }^{7}$ and Olle Hernell ${ }^{8 *}$ \\ ${ }^{1}$ Department of Children Health Care, Children's Hospital of Naniing Medical University, Naniing, China, ${ }^{2}$ Department of \\ Children Health Care, Children's Hospital of Fudan University, Shanghai, China, ${ }^{3}$ Department of Pediatrics, Peking University \\ Third Hospital, Beijing, China, ${ }^{4}$ Arla Foods amba, Arla Innovation Center, Skejby, Denmark, ${ }^{5}$ Arla Foods Ingredients Group \\ P/S, Viby J, Denmark, ${ }^{6}$ Epidemiology and Global Health, Department of Public Health and Clinical Medicine, Umeå \\ University, Umeå, Sweden, ${ }^{7}$ Department of Nutrition, University of California, Davis, Davis, CA, United States, ${ }^{8}$ Department \\ of Clinical Sciences, Pediatrics, Umeå University, Umeå, Sweden
}

Purpose: To evaluate effects on growth and infection rates of supplementing infant formula with the probiotic Lactobacillus paracasei ssp. paracasei strain F19 (F19) or bovine milk fat globule membrane (MFGM).

Methods: In a double-blind, randomized controlled trial, 600 infants were randomized to a formula supplemented with F19 or MFGM, or to standard formula (SF). A breastfed group was recruited as reference $(n=200)$. The intervention lasted from age $21 \pm 7$ days until 4 months, and infants were followed until age one year.

Results: Both experimental formulas were well tolerated and resulted in high compliance. The few reported adverse events were not likely related to formula, with the highest rates in the SF group, significantly higher than for the F19-supplemented infants $(p=0.046)$. Weight or length gain did not differ during or after the intervention among the formula-fed groups, with satisfactory growth. During the intervention, overall, the experimental formula groups did not have more episodes of diarrhea, fever, or days with fever than the breastfed infants. However, compared to the breastfed infants, the SF group had more fever episodes $(p=0.021)$ and days with fever $(p=0.036)$, but not diarrhea. Compared with the breastfed group, the F19-supplemented infants but not the other two formula groups had more visits/unscheduled hospitalizations $(p=0.015)$ and borderline more episodes of upper respiratory tract infections $(p=0.048)$.

Conclusions: Both the MFGM- and F19-supplemented formulas were safe and well-tolerated, leading to few adverse effects, similar to the breastfed group and unlike the SF group. During the intervention, the MFGM-supplemented infants did not differ from the breastfed infants in any primary outcome.

Keywords: infant, breastfed, MFGM, F19, infection, safety, probiotics 


\section{INTRODUCTION}

Breastfeeding is considered the "gold standard" for infant nutrition because human milk offers an adequate supply of nutrients and biologically active components with benefits for growth, development, and protection against infections (1). Infants fed standard formula (SF) are at higher risk of otitis media (2) and gastrointestinal and respiratory infections $(3,4)$. For this reason, a goal of infant formula development is to emulate the composition and functionality of breast milk to close this gap in health outcomes (5). Anti-infectious factors in human milk include immunoglobulins, anti-bacterial and anti-viral proteins, leukocytes, and oligosaccharides, which collectively are considered to reduce the risk of gastrointestinal and other infections in breastfed infants. Studies also strongly suggest that the gut microbiota is associated with positive health outcomes $(6,7)$. Diet is among the main drivers of the composition and function of the gut microbiota (8). In breastfed infants, bifidobacteria and lactobacilli dominate this microbiota, whereas formula-fed infants have a more diverse colonization, including Bacteroidetes, bifidobacteria, staphylococci, Escherichia coli, and Clostridia (9-12). Several meta-analyses have reported that supplementation with a probiotic may be beneficial in preventing and treating upper respiratory tract infections (13), infectious diarrhea, and antibiotic-induced diarrhea (14), as well as allergic disease, e.g., eczema in children (15). Some studies, however, have found no effect of probiotics (16-18). It seems reasonable to develop infant formulas that support establishment of a microbiota resembling that of breastfed infants through the addition of bioactive components or probiotics. A previous study indicated that supplementing with the Lactobacillus paracasei ssp. paracasei strain F19 (F19) during weaning could be an effective tool in prevention of early manifestations of allergy, such as eczema, in infants ages 4-13 months (19). Results of another study suggested a reduced risk of lower respiratory tract infections when this probiotic was combined with prebiotics (20). Collectively, these studies support that F19 is safe, even from the first months of life.

The milk fat globule membrane (MFGM) envelops the triglyceride-rich core of the milk fat globule when secreted from epithelial cells of the lactating mammary gland. This membrane contains numerous biologically active components $(21,22)$, many with antimicrobial effects, e.g., gangliosides (23), oligosaccharides (24), and the glycoproteins butyrophilin, lactadherin, and mucin $(25,26)$. By tradition, infant formulas have been produced from skim milk powder and whey protein concentrate, and the milk fat has been discarded. The fat is typically replaced by a blend of vegetable oils. For this reason, compared to breast milk, infant formulas contain much less of the biologically important MFGM proteins and lipids. Results of a growing number of clinical trials of MFGM supplementation for infants or children support positive effects on both neurodevelopment $(27,28)$ and defense against

Abbreviations: MFGM, milk fat globule membrane; F19, probiotic L. paracasei ssp. paracasei strain F19; SF, standard formula; AE, adverse event; SAE, serious adverse event. infections $(29,30)$. Bovine milk fractions enriched in MFGM are now commercially available, and infant formulas with MFGM have been launched in several countries.

The aim of the present study was to evaluate the effects of feeding infants a SF supplemented with either F19 or MFGM compared to feeding them unsupplemented SF, and using a breastfed group as reference with regard to infant growth and health. The primary hypothesis was that consumption of formula containing either F19 or MFGM would reduce the incidence of infections. Furthermore, we hypothesized that feeding infant formula with F19 or MFGM from the first months of life would be safe and tolerable.

\section{METHODS}

The study was conducted at several centers in China in Nanjing (Children's Hospital of Nanjing Medical University, Nanjing Maternity and Child Health Care Hospital, the Second Affiliated Hospital of Nanjing Medical University, Nanjing Secondary Hospital, and Huaian Maternity and Child Health Hospital), Shanghai (Children's Hospital of Fudan University, Clinical Center for Public Health of Fudan University), and Beijing (Peking University Third Hospital, Beijing Ditan Hospital Capital Medical University, and The First Hospital of Jilin University). It was approved by the institutional review board at the University of California, Davis, as well as the regional ethical review boards in Nanjing, Shanghai, and Beijing, China, and conducted according to the principles in the Declaration of Helsinki. Complete oral and written information about the study was given to the parents/caregivers, and written consent was obtained from the parents or caregivers of all infants before inclusion. The clinical trial was registered at ClinicalTrials.gov (NCT01755481).

\section{Inclusion Criteria and Background Information}

The study was a randomized, double-blind, controlled trial comparing three different infant formulas, with breastfed infants as the reference group. Statistical power calculations revealed that a sample size of 540 infants (180 in each group) was needed to detect a difference of $20 \%$ in incidence of infectious episodes, the primary outcome, with $80 \%$ power (5\% significance). Anticipating a drop-out rate of $15-20 \%$, our aim was to include 800 infants, 200 in each formula group and 200 breastfed infants. Infants were recruited consecutively from December 2013 to August 2016. Inclusion criteria for all infants were gestational age of 37-42 weeks at birth, birth weight $>2,500 \mathrm{~g}$ and $<4,000 \mathrm{~g}$, absence of chronic illness, and a parent or legal representative who could speak and understand Chinese. Exclusion criteria for all infants were malformations, handicaps, or congenital diseases that could affect normal feeding or growth, treatment with antibiotics (including perinatal treatment of the mother), and having been fed infant formula with pre- and/or probiotics. Inclusion criteria for the formula-fed group were healthy infants of mothers who could not or voluntarily completely refrained from breastfeeding at inclusion (infant age $21 \pm 7$ days). 
The exclusion criterion for the formula-fed groups was any breastfeeding at the age of 28 days. Inclusion criterion for the breastfed group was having been exclusively breastfed from birth and mothers intending to breastfeed $>80 \%$ to age at least 4 months. Exclusion criteria for the breastfed group were infants fed $>20 \%$ infant formula of their calculated total intake at 28 days of age. Background information was collected at the time of recruitment. Information on birth weight, feeding pattern, and parental education was recorded for all excluded and dropout infants.

\section{Composition of Infant Formulas}

Formulas were manufactured from bovine milk powder by Arla Foods amba, Denmark. The probiotic bacterium L. paracasei, ssp. paracasei strain F19 was from Chr. Hansen, Denmark, and Lacprodan ${ }^{\circledR}$ MFGM-10 from Arla Foods Ingredients group $\mathrm{P} / \mathrm{S}$, Denmark. The composition of each of the three formulas is shown in Table 1. The final study formulas were produced in Hohhot, China, in accordance with Chinese regulations under strict hygienic conditions, adhering to all prerequisites for human consumption.

\section{Randomization and Intervention}

The intervention was blinded both to parents and staff until analyses were completed. Infants were randomized to one of the three infant formulas: SF; the same formula supplemented with F19 at a dose of $1^{*} 10^{8} \mathrm{cfu} / \mathrm{L}$; or Lacprodan ${ }^{\circledR}$ MFGM-10 (3.88 g Lacprodan ${ }^{\circledR}$ MFGM-10/100 g powder, or $5 \mathrm{~g} / \mathrm{L}$ prepared formula) from inclusion at $21 \pm 7$ days to the end of the fourth month. For randomization, a computerized randomization tool in blocks of 24 was used, stratifying for sex (12 boys and 12 girls) and type of formula coded by color (eight of each color). The block size for the breastfed group was eight (4 boys and 4 girls) in each group. Powdered formula was distributed to families together with preparation instructions in identical boxes marked with a color coded number, prepared at the manufacturing site before being sent to the study site. Prior to the start of intervention, infants were fed SF if formula feeding had been started.

From the beginning of the fifth month to the end of the sixth month of age, all infants in the formula groups received SF. If breast milk supply was insufficient, breastfed infants were fed SF, but not exceeding $20 \%$ of their calculated total intake based on the 3-day formula intake record (see below). Complementary foods were not allowed during the intervention but were introduced no later than 26 weeks of age, according to current recommendations. Vitamin D supplements were given according to current recommendations.

\section{Assessment of Growth}

Visits were made at baseline (inclusion) and at 1, 2, 3, 4, 5, 6,9 , and 12 months of age. At each visit, weight, length, and head circumference were measured. Weight was assessed to the nearest $10 \mathrm{~g}$. The same electronic weighing scales (Seca 757; Seca, Germany) were used for all infants at all visits at each center and calibrated at the first visit and every visit thereafter until the end of the study. Recumbent length was measured to nearest $1 \mathrm{~mm}$
TABLE 1 | Composition of infant formulas used in the study.

\begin{tabular}{|c|c|c|c|}
\hline & $\mathrm{SF}^{\mathrm{a}}$ & MFGM & F19 \\
\hline Energy (kcal/100 mL) & 66 & 67 & 66 \\
\hline Protein $(\mathrm{g} / 100 \mathrm{~mL})$ & 1.6 & 1.5 & 1.6 \\
\hline Casein (g/100 mL) & 0.60 & 0.59 & 0.60 \\
\hline Whey (g/100 mL) & 0.99 & 0.95 & 0.97 \\
\hline Carbohydrate (g/100 mL) & 7.0 & 7.3 & 7.0 \\
\hline Fat $(\mathrm{g} / 100 \mathrm{~mL})$ & 3.5 & 3.6 & 3.5 \\
\hline Linoleic acid (g/100 mL) & 0.7 & 0.7 & 0.7 \\
\hline$\alpha$-Linolenic acid $(\mathrm{mg} / 100 \mathrm{~mL})$ & 64 & 65 & 64 \\
\hline $\mathrm{DHA}^{\mathrm{b}}$ (\% of total fatty acids) & 0.33 & 0.31 & 0.29 \\
\hline ARA ( $\%$ of total fatty acids) & 0.45 & 0.43 & 0.39 \\
\hline \multicolumn{4}{|l|}{ Minerals } \\
\hline Sodium (mg/100 mL) & 20 & 20 & 20 \\
\hline Potassium (mg/100 mL) & 67 & 62 & 67 \\
\hline Copper ( $\mu \mathrm{g} / 100 \mathrm{~mL})$ & 61 & 59 & 61 \\
\hline Magnesium (mg/100 mL) & 8.1 & 8.0 & 8.1 \\
\hline Iron (mg/100 mL) & 0.81 & 0.81 & 0.81 \\
\hline Zinc (mg/100 mL) & 0.6 & 0.6 & 0.6 \\
\hline Manganese $(\mu \mathrm{g} / 100 \mathrm{~mL})$ & 8.5 & 8.1 & 8.5 \\
\hline Calcium (mg/100 mL) & 50 & 49 & 50 \\
\hline Phosphorus (mg/100 mL) & 36 & 34 & 36 \\
\hline lodine $(\mu \mathrm{g} / 100 \mathrm{~mL})$ & 11 & 12 & 11 \\
\hline Chloride (mg/100 mL) & 47 & 48 & 47 \\
\hline Selenium ( $\mu \mathrm{g} / 100 \mathrm{~mL})$ & 2.5 & 2.3 & 2.5 \\
\hline \multicolumn{4}{|l|}{ Vitamins } \\
\hline Vitamin C (mg/100 mL) & 9.1 & 9.3 & 9.1 \\
\hline Vitamin A ( $\mu \mathrm{gRE} / 100 \mathrm{~mL})$ & 85 & 81 & 85 \\
\hline Vitamin $E(m g \alpha-T E / 100 m L)$ & 1.2 & 1.2 & 1.2 \\
\hline Vitamin D ( $\mu \mathrm{g} / 100 \mathrm{~mL})$ & 1.0 & 1.1 & 1.0 \\
\hline Vitamin K1 $(\mu \mathrm{g} / 100 \mathrm{~mL})$ & 5.4 & 5.2 & 5.4 \\
\hline Vitamin B1 $(\mu \mathrm{g} / 100 \mathrm{~mL})$ & 86.1 & 88.0 & 86.1 \\
\hline Vitamin B2 ( $\mu \mathrm{g} / 100 \mathrm{~mL})$ & 211 & 159 & 211 \\
\hline Vitamin B6 ( $\mu \mathrm{g} / 100 \mathrm{~mL})$ & 80.3 & 72.4 & 80.3 \\
\hline Vitamin B12 ( $\mu \mathrm{g} / 100 \mathrm{~mL})$ & 0.4 & 0.3 & 0.4 \\
\hline Niacin ( $\mu \mathrm{g} / 100 \mathrm{~mL})$ & 742 & 761 & 742 \\
\hline Folic acid ( $\mu \mathrm{g} / 100 \mathrm{~mL})$ & 17.0 & 15.7 & 17.0 \\
\hline Pantothenic acid ( $\mu \mathrm{g} / 100 \mathrm{~mL})$ & 644 & 575 & 644 \\
\hline Biotin $(\mu \mathrm{g} / 100 \mathrm{~mL})$ & 2.8 & 2.4 & 2.8 \\
\hline \multicolumn{4}{|l|}{ Optional ingredients } \\
\hline Choline (mg/100 mL) & 10.7 & 8.9 & 10.7 \\
\hline Inositol (mg/100 mL) & 4.6 & 4.8 & 4.6 \\
\hline Lutein ( $\mu \mathrm{g} / 100 \mathrm{~mL})$ & 9.6 & 8.8 & 9.6 \\
\hline Nucleotide $(\mathrm{mg} / 100 \mathrm{~mL})$ & 2.9 & 3.0 & 2.9 \\
\hline Taurine (mg/100 mL) & 6.2 & 5.8 & 6.2 \\
\hline L-carnitine (mg/100 mL) & 1.9 & 1.7 & 1.9 \\
\hline
\end{tabular}

a SF, standard formula; MFGM, formula supplemented with Lacprodan ${ }^{\circledR}$ MFGM-10; F19, formula supplemented with L. paracasei ssp. paracasei strain F19.

${ }^{b} D H A$, docosahexaenoic acid; ARA, arachidonic acid.

${ }^{C} A$ mixture of disodium salts of 5'-AMP, 5'-CMP, 5'-GMP, 5'-UMP, and 5'-IMP.

using a standardized length board (Seca 416; Seca, Germany). Head circumference was measured to the nearest $1 \mathrm{~mm}$ using a standard non-elastic plastic-coated measuring tape (Seca 212, 
Seca, Germany). Anthropometric data are presented as z-scores calculated from the World Health Organization reference growth standards for breastfed infants (31).

\section{Formula Intake}

Parents of formula-fed infants were asked to complete a 3-day formula intake diary every month from inclusion until the end of the fifth month of age. Parents or caregivers of breastfed infants were asked to note all formula fed to the infant to allow the study staff to check adherence with breast milk consumption.

\section{Assessment of Episodes of Infections and Health}

From inclusion until 12 months of age, the incidence and duration of infectious episodes (acute diarrhea, upper and lower acute respiratory tract infections, fever) were diagnosed and recorded by the study physician based on the following definitions: Acute diarrhea was defined as three or more watery stools within a 24-h period or loose-to-watery bowel movements that exceeded the infant's usual daily stool frequency by two or more stools. Acute respiratory infections were defined as presence of two or more of the following symptoms as reported by the parent/caretaker: nasal discharge (clear, cloudy, yellow, or green), cough, fever, rapid, labored and/or noisy breathing, wheezing, chest in-drawing, flaring of nostrils, ear pain and/or discharge, and cyanosis. Respiratory symptoms that occurred within 2 weeks of the beginning of the illness were defined as part of the same episode. Symptoms presented more than 2 weeks after the start of an incident were considered as a new episode. Parent-reported number of episodes and days with fever $\left(>38^{\circ} \mathrm{C}\right)$, vomiting, use of antibiotics, unscheduled doctor's visits, and hospitalization (incidence, duration, diagnosis, and treatment) were registered based on reviews performed every second week by the study physician. The length of the period of antibiotic use was recorded. Stool consistency was registered as watery diarrhea, loose, soft formed, or hard in the monthly 3day dietary and health record. Parents/caretakers whose infants dropped out were asked to remain in the study for follow-up on an intention-to-treat basis.

\section{Definition of Adverse Event and Serious Adverse Event}

An adverse event (AE) was defined as any untoward occurrence in an infant administered a test product and that did not necessarily have to have a causal relationship with the product. AEs were illnesses, signs, or symptoms (including an abnormal laboratory finding) occurring or worsening during the course of the study. A serious adverse event (SAE) was a fatal or life-threatening event causing permanent harm or requiring/extending inpatient treatment at a hospital, or that the physician considered medically relevant.

All AEs were documented on the case report form. In the case of a SAE persisting beyond the trial termination, a follow-up visit was required. Furthermore, study physicians analyzed each report for a potential cause-effect relationship between the study products and the AE. Cow's milk protein allergy was diagnosed by a physician as follows: elimination of cow's milk protein/formula with disappearance of symptoms and reappearance of the same symptoms on reintroduction of milk protein/formula. When diagnosed, infants were recommended a protein hydrolysate formula and were considered study drop-outs.

\section{Blood Sample Collection and Storage}

All infants had a venous blood sample of $0.5-2 \mathrm{~mL}$ collected by the study staff on two occasions, one at the end of the intervention when the infants were age 4 months. After centrifugation at 1,500 rpm for $10 \mathrm{~min}$, serum was collected and immediately frozen and stored at $-80^{\circ} \mathrm{C}$ until shipped on dry ice to the sites of analyses.

\section{Stool Sample Collection and Storage}

Parents/legal representatives were asked to collect stool samples at different time points, including at the end of the intervention period. Before collection of the first stool sample, a reusable isolated bag for transportation of the stool samples, a reusable freezing body, two containers for the stool samples, a plastic bag for the filled containers, gloves, and instructions for collection, storage, and transportation of the stool samples were provided to the parent or the infant's legal representative. Stool samples were collected in the containers, put in the plastic bag, and stored in a freezer $\left(-20^{\circ} \mathrm{C}\right)$ until the day of the visit. The frozen stool samples were transported to the study site, where they were stored at $-20^{\circ} \mathrm{C}$ until shipped on dry ice for analysis (TNO, The Hague, Netherlands).

\section{Serum Ferritin}

Serum ferritin was analyzed in infants at age 4 months, with an enzyme-linked immunosorbent assay kit (RayBiotech, Norcross, GA, USA). This kit uses a biotinylated antibody specific for human ferritin and horseradish peroxidase-conjugated streptavidin. Samples were run in duplicate, and values are presented as means.

\section{Fecal DNA Extraction and qPCR}

DNA from fecal samples collected at the end of the intervention was isolated as previously described (32) with some minor modifications. The samples were initially mixed with $250 \mu \mathrm{L}$ lysis buffer (Agowa, Berlin, Germany), $250 \mu \mathrm{L}$ zirconium beads $(0.1 \mathrm{~mm})$, and $200 \mu \mathrm{L}$ phenol, before being introduced to a BeadBeater (BioSpec Products, Bartlesville, OK, USA) for two $\times 2$ min. Quantitative PCR detection was performed with the primers and according to conditions described previously (33). To evaluate if samples contained F19, data were plotted from low to high $\mathrm{Ct}$, resulting in an S-shaped curve, with true positives in the lower and true negatives in the higher end, as previously described (33).

\section{Statistics}

Comparison of means among the MFGM, and F19 groups and the SF group were done pair-wise with independent samples $t$-tests. In the case of skewed distributions, comparisons were performed with Mann-Whitney U-test. Categorical variables were compared pair-wise using the Chi square test or Fisher's exact test. Comparisons of treatment groups with the breastfed 
group were also done pair-wise. Analysis of variance was used for analyzing ferritin concentrations among groups.

Only adjusted $p$-values are presented in the text. Adjustment was based on the Bonferroni method. Per-protocol analyses were based on the 674 children who completed the study. There were no significant differences among the three sites with respect to birth weight, sex distribution, or education level, or with respect to major outcomes. All calculations were done using SPSS v 23
(IBM SPSS Statistics, Armonk, NY). Significance level was set to $5 \%$.

\section{RESULTS}

In total, 799 children were recruited and randomized to formulafed groups or recruited to the breastfed reference group. Ten infants did not attend any of the visits. Thus, 789 children

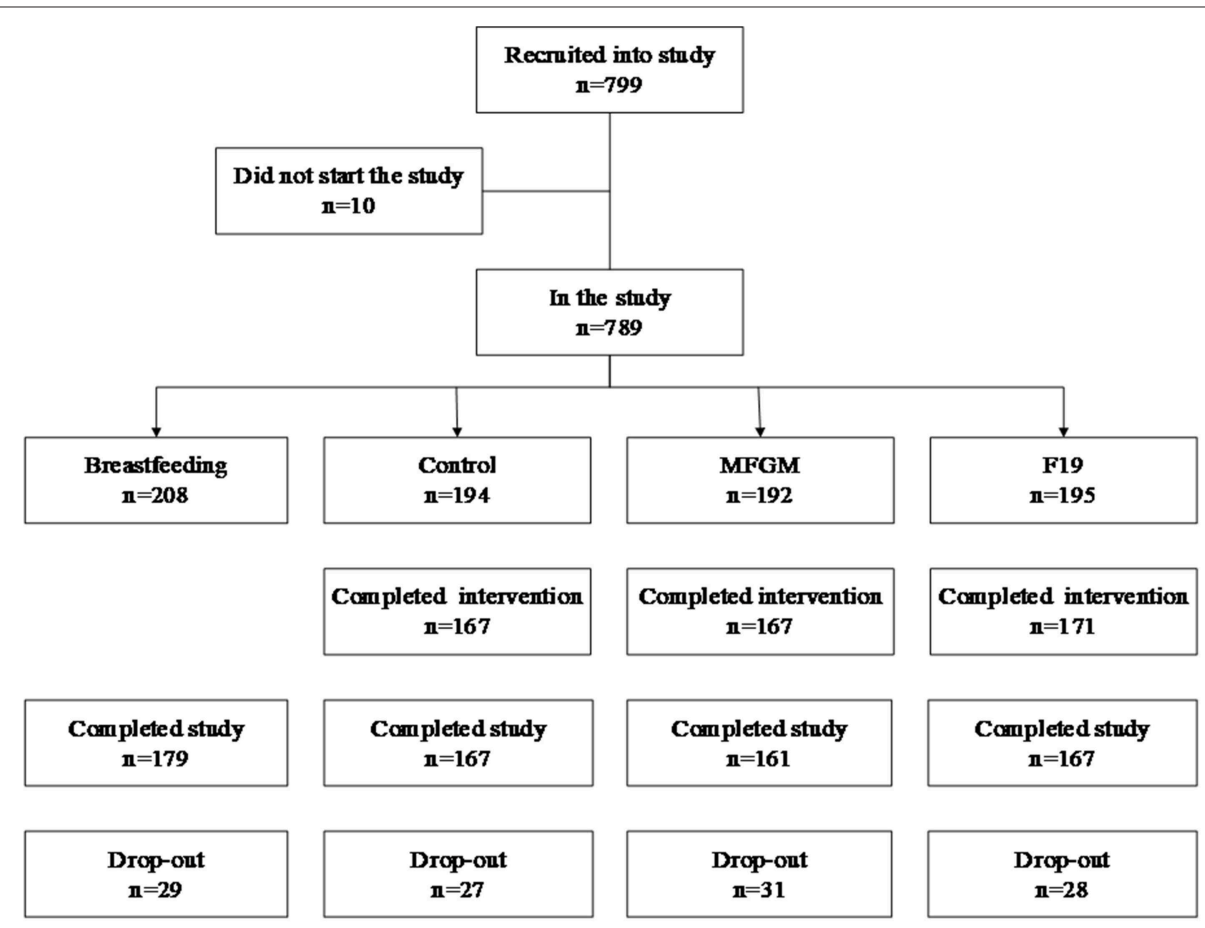

FIGURE 1 | Drop-out rates and adherence to the intervention in the formula-fed groups (SF, standard formula; MFGM, formula supplemented with milk fat globule membrane; F19, formula supplemented with L. paracasei ssp. paracasei strain F19) and the BF (breastfed) group. Ten children did not show up at any of the examinations and were excluded. During the study, 115 children left the study at various times, giving a total drop-out rate of 14.6\% (BF, 14.1; SF, 14.1; MFGM, 17.9, and F19, 15.1\%) with no significant difference among groups. The most common reason for drop-out (78\%) was parent/caregiver decision to do so without explanation.

TABLE 2 | Demographic characteristics of the formula-fed and breastfed groups.

\begin{tabular}{|c|c|c|c|c|}
\hline Variables & $\begin{array}{c}\text { BF } \\
(n=208)\end{array}$ & $\begin{array}{c}\text { SF } \\
(n=194)\end{array}$ & $\begin{array}{c}\text { MFGM } \\
(n=192)\end{array}$ & $\begin{array}{c}\text { F19 } \\
(n=195)\end{array}$ \\
\hline Birth weight (g), mean (SD) & $3381(314)$ & $3298(374)$ & 3279 (399) & $3281(412)$ \\
\hline Sex, girls (\%) & 52.9 & 49.5 & 51.6 & 49.7 \\
\hline Gestational age (weeks) & 39.0 & 38.7 & 38.8 & 38.8 \\
\hline Siblings (\% with no siblings) & 75.5 & 61.9 & 64.1 & 61.5 \\
\hline Mother's age (years), mean (SD) & $29.4(3.5)$ & $29.6(4.6)$ & $29.2(4.3)$ & $29.5(4.5)$ \\
\hline Father's age (years), mean (SD) & $31.3(4.4)$ & $31.4(5.2)$ & $31.1(4.9)$ & $31.6(6.1)$ \\
\hline Mother's education (\%) & $4.3 / 25.0 / 70.7$ & $9.8 / 47.9 / 41.2$ & $9.9 / 44.3 / 44.8$ & $9.2 / 40.5 / 46.7$ \\
\hline Father's education (\%) & $3.8 / 21.2 / 74.5$ & $9.3 / 47.4 / 42.3$ & $7.3 / 41.7 / 49.0$ & $9.7 / 43.6 / 44.6$ \\
\hline
\end{tabular}

BF, breastfed reference group; SF, standard formula; MFGM, formula supplemented with milk fat globule membrane; F19, formula supplemented with L. paracasei ssp. paracasei strain F19; SD, standard deviation.

Education (\%) refers to low/middle/high education level, i.e., $\leq 12 \mathrm{y} / 13-15 \mathrm{y} / \geq 16 \mathrm{y}$ of school and university education. 
remained for intention-to-treat analyses. In these analyses, missing continuous values were replaced according to "carry forward last value." Missing categorical values were replaced with zero (Figure 1).

\section{Adherence}

During the intervention, no formula consumption was reported for 22 formula-fed children, 42 children had consumption reported for 1, 2, or 3 months, and 505 children had consumption reported for the whole intervention. The proportion of children adherent for the whole intervention period did not differ significantly among the formula-fed groups. Average formula consumption during the intervention for the SF, MFGM, and F19 groups was 876, 866, and $833 \mathrm{~mL} /$ day, respectively. The F19 group consumed a lower average volume than the SF group $(p=0.020)$, but there was no difference between the SF and MFGM groups. Analysis of F19 in the stool in a randomized subsample of 100 from each of the formula-fed groups at age 4 months showed that $92 \%$ of the infants in the F19 group carried F19 compared to none in the other formula groups, confirming high adherence (data not shown).

\section{Demographic Characteristics}

Basic characteristics for the groups are shown in Table 2. There was no significant difference in birth weight, sex distribution, gestational age, type of delivery, pregnancy complications, parental education level, or proportion of no siblings among the formula-fed groups. However, birth weight $(p=0.002)$, parental education level $(p<0.013)$, and proportion of no siblings $(p=0.001)$ were lower for the formula-fed groups combined than for the breastfed group.

\section{Anthropometrics}

Weight $\mathrm{z}$-scores did not differ significantly among the formulafed groups at any time point. Mean weight for the breastfed group was significantly higher than for the F19 group until age 2 months ( $p=0.015$ and 0.028 at 1 and 2 months, respectively) and for the SF and MFGM groups until age 4 months (all $p \leq 0.041$ ). After these ages, the groups showed no significant differences (Figure 2A and Table 3). During the intervention, weight gain (g/day) did not differ among the formula-fed groups or between the formula-fed groups overall and the breastfed group. However, at 5-12 months, weight gain in the MFGM group was slightly (1.1 $\mathrm{g}$ /day) but significantly higher compared to the breastfed group $(p=0.012)$ (Table 4).

Z-scores for body length did not differ significantly among the formula-fed groups at any time point (Figure 2B and Table 3). The SF and MFGM groups did not differ significantly from the breastfed group at any time point, but the F19 infants had significantly greater length at ages $9(p=0.009)$ and 12 months $(p=0.048)$. Gain in body length $(\mathrm{cm} /$ day) did not differ among any of the groups during or after the intervention (Table 4).

Head circumference $z$-scores did not differ significantly among the formula-fed groups at any time between 1 and 12 months (Figure 2C and Table 3). During the intervention, the breastfed group had larger head circumference than all of the formula-fed groups at 1 and 2 months (MFGM, $p=0.012$ and

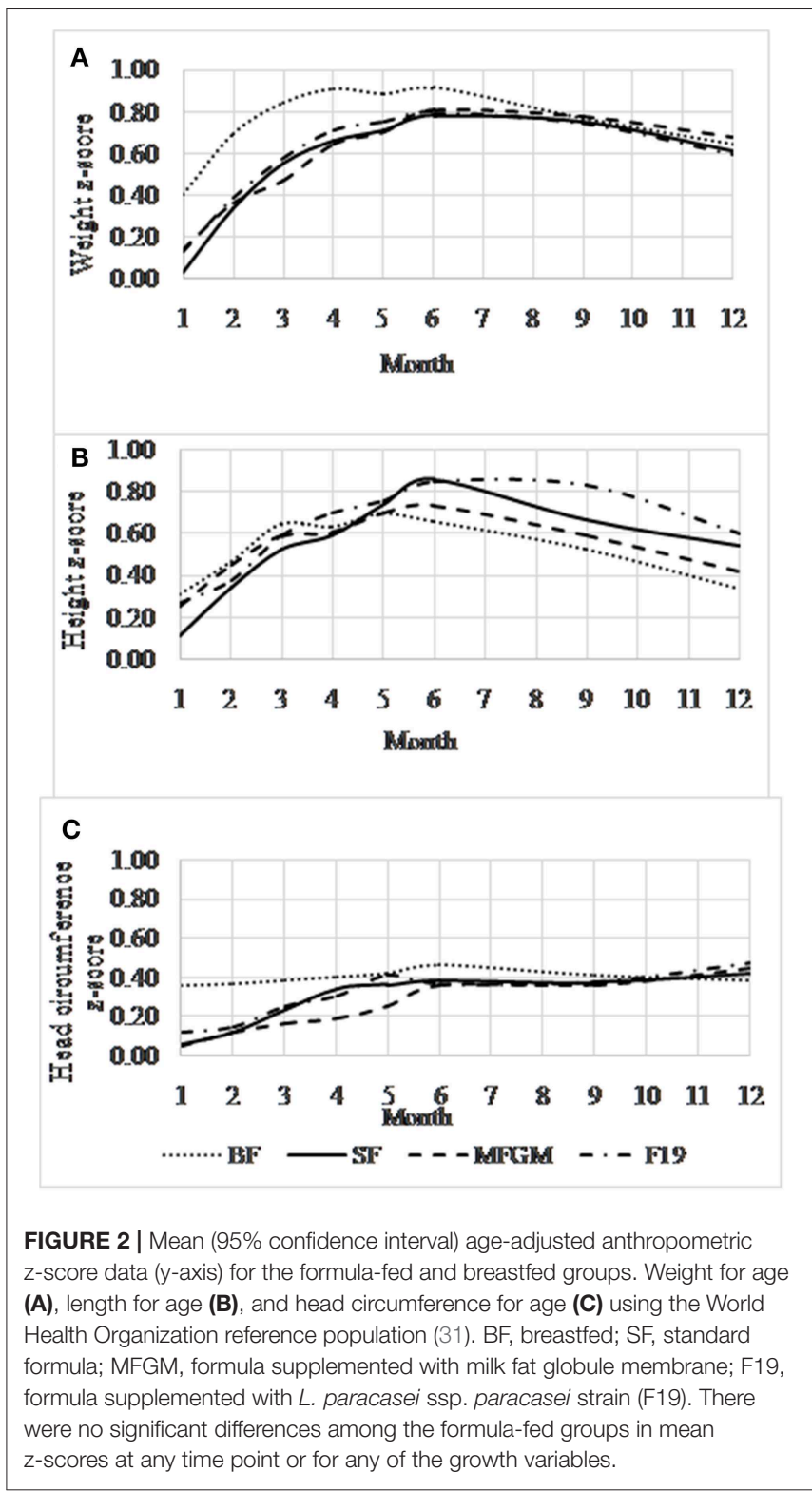

$p=0.048$, respectively; F19, $p=0.051$ and 0.042 , respectively; SF, $p=0.003$ and 0.024 , respectively). After the intervention, the groups showed no differences in head circumference or in gains in head circumferences (Table 4).

\section{Primary Outcomes}

During the intervention, both the MFGM and the F19 groups had numerically fewer episodes of fever $\left(>38^{\circ} \mathrm{C}\right)$ and days with fever than the SF group, although the differences did not reach statistical significance. However, compared to the breastfed group, the SF infants had significantly more fever episodes ( $p$ $=0.021)$ and days with fever $(p=0.036)$, but not episodes of diarrhea. In contrast, neither the MFGM nor the F19 groups had significantly more episodes of fever or number of days with fever than the breastfed group (Table 5). 
TABLE 3 | Weight, height and head circumference from 1 to 12 months of age.

\begin{tabular}{|c|c|c|c|c|c|c|}
\hline & BF & SF & MFGM & F19 & $\begin{array}{l}\text { SF vs. } \\
\text { MFGM }\end{array}$ & $\begin{array}{c}\text { SF vs. } \\
\text { F19 }\end{array}$ \\
\hline & $(n=208)$ & $(n=194)$ & $(n=192)$ & $(n=195)$ & $p$-values & $p$-values \\
\hline \multicolumn{7}{|c|}{ WEIGHT (KG) } \\
\hline 1 month & 4.6 & 4.4 & 4.4 & 4.4 & 0.612 & 0.532 \\
\hline 2 months & 5.8 & 5.6 & 5.6 & 5.7 & 0.999 & 0.746 \\
\hline 3 months & 6.8 & 6.6 & 6.5 & 6.6 & 0.836 & 0.999 \\
\hline 4 months & 7.5 & 7.3 & 7.2 & 7.3 & 0.999 & 0.999 \\
\hline 5 months & 8.0 & 7.8 & 7.8 & 7.8 & 0.999 & 0.999 \\
\hline 6 months & 8.4 & 8.4 & 8.4 & 8.4 & 0.999 & 0.999 \\
\hline 9 months & 9.4 & 9.4 & 9.4 & 9.4 & 0.999 & 0.999 \\
\hline 12 months & 10.2 & 10.1 & 10.2 & 10.1 & 0.900 & 0.999 \\
\hline \multicolumn{7}{|c|}{ HEIGHT (CM) } \\
\hline 1 month & 54.8 & 54.4 & 54.7 & 54.7 & 0.432 & 0.310 \\
\hline 2 months & 58.7 & 58.5 & 58.6 & 58.5 & 0.828 & 0.999 \\
\hline 3 months & 61.9 & 61.7 & 61.8 & 61.8 & 0.999 & 0.999 \\
\hline 4 months & 64.3 & 64.3 & 64.2 & 64.5 & 0.999 & 0.780 \\
\hline 5 months & 66.4 & 66.6 & 66.4 & 66.6 & 0.999 & 0.999 \\
\hline 6 months & 68.1 & 68.6 & 68.3 & 68.5 & 0.390 & 0.999 \\
\hline 9 months & 72.2 & 72.6 & 72.4 & 73.0 & 0.848 & 0.240 \\
\hline 12 months & 75.7 & 76.2 & 75.9 & 76.4 & 0.472 & 0.999 \\
\hline \multicolumn{7}{|c|}{ HEAD CIRCUMFERENCE (CM) } \\
\hline 1 month & 37.3 & 37.0 & 37.0 & 37.0 & 0.999 & 0.999 \\
\hline 2 months & 39.1 & 38.8 & 38.8 & 38.9 & 0.999 & 0.999 \\
\hline 3 months & 40.4 & 40.3 & 40.2 & 40.3 & 0.802 & 0.999 \\
\hline 4 months & 41.6 & 41.5 & 41.3 & 41.4 & 0.292 & 0.590 \\
\hline 5 months & 42.5 & 42.5 & 42.4 & 42.5 & 0.999 & 0.999 \\
\hline 6 months & 43.3 & 43.2 & 43.2 & 43.2 & 0.956 & 0.999 \\
\hline 9 months & 44.9 & 44.9 & 44.8 & 44.9 & 0.999 & 0.999 \\
\hline 12 months & 46.0 & 46.1 & 46.1 & 46.1 & 0.999 & 0.999 \\
\hline
\end{tabular}

BF, breastfed reference group; SF, standard formula; MFGM, formula supplemented with milk fat globule membrane; F19, formula supplemented with Lactobacillus paracasei ssp. paracasei strain F19.

During the intervention, the number of episodes of upper respiratory tract infections did not differ among the formulafed groups or between these groups overall and breastfed infants; however, the F19 group had more episodes than the breastfed group $(p=0.048)$. The F19 infants also had more episodes of lower respiratory tract infections than the breastfed group $(p=0.009)$.

During the post-intervention period (5-12 months), the formula-fed groups did not differ significantly for any of the primary outcomes except for marginally more episodes of upper respiratory tract infections for the MFGM infants compared to the SF group $(p=0.050)$. Compared to the breastfed infants, the MFGM group had more episodes of diarrhea $(p=0.021)$ (Table 5). Per-protocol analyses of the primary outcomes did not differ from the intention-to-treat analyses (data not shown).

\section{Secondary Outcomes}

During the intervention, the formula-fed groups did not differ with respect to skin affections, use of antibiotics, vomiting, or unscheduled visits/hospitalizations (Table 6). However, compared to the breastfed group, the F19 infants used significantly more antibiotics and had more unscheduled visits and/or hospitalization episodes $(p=0.045$ and 0.015 , respectively). After the intervention, only the F19 group used more antibiotics compared to the breastfed infants $(p=0.003)$, with no difference among the formulafed groups. None of the formula-fed infants had more unscheduled visits/hospitalizations than the breastfed group after the intervention.

\section{Adverse Events}

The number of AEs was low, with no differences within any of the reported categories among the formula-fed groups or between breastfed and formula-fed infants during the intervention or the post-intervention period (Table 7). However, during the intervention, the total number of AEs was highest in the SF group and significantly higher than in the F19 group $(p=0.046)$, but with no significant difference after the intervention. 
TABLE 4 | Mean weight/length/head circumference gain during 0-4 months and 5-12 months.

\begin{tabular}{|c|c|c|c|c|c|c|}
\hline & BF & SF & MFGM & F19 & $\begin{array}{l}\text { SF vs. } \\
\text { MFGM }\end{array}$ & $\begin{array}{c}\text { SF vs. } \\
\text { F19 }\end{array}$ \\
\hline & $(n=208)$ & $(n=194)$ & $(n=192)$ & $(n=195)$ & $p$-values & $p$-values \\
\hline \multicolumn{7}{|l|}{ 0-4 MONTHS } \\
\hline Weight gain (g/day) & 31.5 & 31.7 & 30.9 & 31.7 & 0.508 & 0.999 \\
\hline Length gain (cm/day) & 0.104 & 0.107 & 0.104 & 0.106 & 0.276 & 0.999 \\
\hline Head circumference (cm/day) & 0.047 & 0.050 & 0.048 & 0.047 & 0.698 & 0.912 \\
\hline \multicolumn{7}{|l|}{ 5-12 MONTHS } \\
\hline Weight gain (g/day) & 10.3 & 10.8 & 11.4 & 10.9 & 0.224 & 0.999 \\
\hline Length gain (cm/day) & 0.044 & 0.045 & 0.044 & 0.046 & 0.656 & 0.999 \\
\hline Head circumference (cm/day) & 0.017 & 0.017 & 0.017 & 0.017 & 0.112 & 0.999 \\
\hline
\end{tabular}

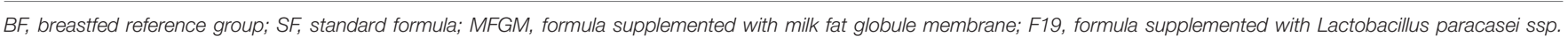
paracasei strain F19.

TABLE 5 | Primary outcomes during 0-4 months and 5-12 months.

\begin{tabular}{|c|c|c|c|c|c|c|}
\hline & BF & SF & MFGM & F19 & $\begin{array}{l}\text { SF vs. } \\
\text { MFGM }\end{array}$ & $\begin{array}{c}\text { SF vs. } \\
\text { F19 }\end{array}$ \\
\hline & $(n=208)$ & $(n=194)$ & $(n=192)$ & $(n=195)$ & $p$-values & $p$-values \\
\hline \multicolumn{7}{|l|}{ 0-4 MONTHS } \\
\hline Diarrhea (episodes) & 14 & 9 & 7 & 15 & 0.999 & 0.532 \\
\hline Fever $>38^{\circ} \mathrm{C}$ (episodes) & 6 & 21 & 11 & 10 & 0.242 & 0.214 \\
\hline Days with fever & 8 & 31 & 18 & 11 & 0.230 & 0.122 \\
\hline \multicolumn{7}{|l|}{ Other infections (episodes) } \\
\hline URI & 18 & 27 & 28 & 33 & 0.999 & 0.966 \\
\hline LRI & 0 & 5 & 2 & 8 & 0.898 & 0.999 \\
\hline \multicolumn{7}{|l|}{ 5-12 MONTHS } \\
\hline Diarrhea (episodes) & 25 & 34 & 45 & 36 & 0.422 & 0.999 \\
\hline Fever $>38^{\circ} \mathrm{C}$ (episodes) & 77 & 85 & 94 & 79 & 0.908 & 0.999 \\
\hline Days with fever & 179 & 197 & 224 & 185 & 0.999 & 0.999 \\
\hline \multicolumn{7}{|l|}{ Other infections (episodes) } \\
\hline URI & 82 & 82 & 104 & 101 & 0.050 & 0.136 \\
\hline LRI & 3 & 5 & 3 & 8 & 0.999 & 0.999 \\
\hline
\end{tabular}

BF, breastfed reference group; SF, standard formula; MFGM, formula supplemented with milk fat globule membrane; F19, formula supplemented with Lactobacillus paracasei ssp. paracasei strain F19; URI, upper respiratory tract infection; LRI, lower respiratory tract infection.

In total, 20 infants had SAEs, and one infant had two events. The SAEs were distributed among the groups as follows: breastfed, four; SF, four; MFGM, seven; and F19, six. The most common SAE was lower respiratory tract infection, with 16 episodes. During the intervention period, there were six SAEs, three among breastfed infants, one in the MFGM group, and two in the F19 group.

Of all the reported AEs and SAEs, 12 were considered probably related to the formula and one definitely related by the responsible pediatrician. Eleven of the infants developed skin affections and one infant constipation. Four of the infants had no treatment for their skin affections, five had local treatment with lubricant and/or steroids, and one infant also local antibiotics. The formula was switched to another formula by the parents of one infant (constipation), and 3 days later this infant dropped out from the study. For another infant, the formula was switched to a partially hydrolyzed formula. This infant had a skin infection and was treated with local steroids and antibiotics. Whether the switch of formula had an effect is unknown. For a third infant, formula was also withdrawn, and the mother went back to exclusive breastfeeding. The only infant for whom the skin affection was classified as definitely related to the formula stopped eating the formula, but the diagnosis was never proven by challenging the infant with the formula. This infant belonged to the MFGM group. The 12 infants experiencing these events were distributed across all groups: SF, four; F19, four; MFGM, two; and breastfed, two. Thus, the AEs possibly related to the formula were few and not proven in any of the infants, and there was no significant difference among the groups. 
TABLE 6 | Secondary outcomes during 0-4 months and 5-12 months.

\begin{tabular}{|c|c|c|c|c|c|c|}
\hline & BF & SF & MFGM & F19 & $\begin{array}{l}\text { SF vs. } \\
\text { MFGM }\end{array}$ & $\begin{array}{c}\text { SF vs. } \\
\text { F19 }\end{array}$ \\
\hline & $(n=208)$ & $(n=194)$ & $(n=192)$ & $(n=195)$ & $p$-values & $p$-values \\
\hline \multicolumn{7}{|l|}{ 0-4 MONTHS } \\
\hline Skin effects & 17 & 20 & 16 & 16 & 0.999 & 0.980 \\
\hline Use of antibiotics & 7 & 21 & 9 & 19 & 0.128 & 0.999 \\
\hline Vomiting & 0 & 0 & 1 & 0 & - & - \\
\hline Unscheduled visits and/or hospitalization & 9 & 23 & 15 & 25 & 0.986 & 0.798 \\
\hline \multicolumn{7}{|l|}{ 5-12 MONTHS } \\
\hline Skin infections & 4 & 0 & 2 & 0 & 0.480 & - \\
\hline Use of antibiotics & 33 & 50 & 53 & 65 & 0.999 & 0.506 \\
\hline Vomiting & 0 & 1 & 0 & 0 & - & - \\
\hline Unscheduled visits and/or hospitalization & 45 & 54 & 55 & 70 & 0.720 & 0.708 \\
\hline
\end{tabular}

BF, breastfed reference group; SF, standard formula; MFGM, formula supplemented with milk fat globule membrane; F19, formula supplemented with Lactobacillus paracasei ssp. paracasei strain F19.

\section{S-Ferritin}

S-ferritin concentration was analyzed in a random sample consisting of 50 infants from each of the groups (Figure 3). There was no difference in s-ferritin results among the formula-fed groups, but values in the F19 group were significantly lower than in the breastfed group $(p=0.008)$. The SF and MFGM groups did not differ from the breastfed infants. There was a sex difference in $s$-ferritin in all groups, with girls having higher values, and values for girls differed significantly from boys for the breastfed and F19 groups. The number of infants with iron deficiency, defined as sferritin $<12 \mu \mathrm{g} / \mathrm{L}$, was two each in the breastfed and F19 groups and one each in the SF and MFGM groups.

\section{DISCUSSION}

In this randomized, double-blind, controlled multicenter study, we evaluated the safety and effects on infections and growth of two infant formulas, one supplemented with the probiotic bacterium L. paracasei, ssp. paracasei strain F19 and the other with the bovine MFGM fraction Lacprodan ${ }^{\circledR}$ MFGM-10, as compared to the same unsupplemented standard infant formula. A breastfed group served as reference.

All three formulas were well accepted by the infants as well as the parents/care providers. Although the F19 group consumed slightly less formula per day than the SF group, all formulafed groups had a higher average intake of formula during the intervention than recommended by the manufacturer, suggesting satisfactory adherence. This inference is further supported by the fact that of the 100 infants randomized in each group at 4 months, $92 \%$ of the F19 infants had detectable F19 in their stool, compared with none in the other two groups (data not shown).

Growth is an important safety outcome for any new ingredient used in infant formula (34). The formula-fed groups showed no difference from each other in weight, length, or head circumference $z$-scores at any time point. Compared with the breastfed reference group, at entry, infants assigned to the formula-fed groups were smaller, particularly with lower weight because of lower birth weight. This baseline difference is a reasonable explanation for why particularly early anthropometric measures (1-4 months) were higher for the breastfed group than for the formula-fed groups. A higher weight among breastfed infants compared to formula-fed infants early in life has been described in many studies $(35,36)$, as has also that this difference disappears after age 4-6 months. Average daily gain in weight, length, or head circumference did not differ among the formula-fed groups or between these infants overall and the breastfed group during the intervention. A previous report indicated that providing F19 during the weaning period does not affect body composition, growth, or any of the assessed metabolic markers at school age (37), and another study showed that supplementing an infant formula with the same MFGM fraction as used here did not affect growth (29). Overall, the anthropometric data for the MFGM and F19 groups did not differ from those of the SF group, taking the difference in size at birth into consideration. All three formulafed groups showed growth patterns similar to formula-fed infants in other published studies and tracked with the World Health Organization growth charts.

We identified few AEs overall, with no differences within any of the AE categories among the formula-fed groups or between the breastfed and formula-fed groups during the intervention or the post-intervention period. The total number of AEs during the intervention was numerically higher among SF infants than in other groups, significantly so compared to the F19 group, but no groups differed after the intervention. Only 20 infants experienced SAEs, most commonly lower respiratory tract infections, with 16 episodes. Taking AEs and SAEs together, in no case could it be definitely concluded that the formula was the cause. A recent study from China from one of the study sites showed low iron status in both breastfed and formula-fed infants (38). In the present study, we found very few infants with iron deficiency, and overall iron status was satisfactory in all groups. The reason for this discrepancy is not known, but many factors 
TABLE 7 | Adverse events during 0-4 months and 5-12 months.

\begin{tabular}{|c|c|c|c|c|c|c|}
\hline & BF & SF & MFGM & F19 & $\begin{array}{l}\text { SF vs. } \\
\text { MFGM }\end{array}$ & $\begin{array}{c}\text { SF vs. } \\
\text { F19 }\end{array}$ \\
\hline & $(n=208)$ & $(n=194)$ & $(n=192)$ & $(n=195)$ & $p$-values & $p$-values \\
\hline \multicolumn{7}{|l|}{ 0-4 MONTHS } \\
\hline Oral infections & 1 & 2 & 1 & 1 & & \\
\hline Gastrointestinal infections ${ }^{a}$ & 1 & 4 & 3 & 0 & & \\
\hline Other viral infections & 1 & 0 & 0 & 0 & & \\
\hline Other bacterial infections & 0 & 0 & 1 & 0 & & \\
\hline Hematochezia & 0 & 2 & 0 & 0 & & \\
\hline Constipation & 1 & 2 & 1 & 0 & & \\
\hline Other non-infectious diseases & 0 & 1 & 0 & 0 & & \\
\hline Skin effects & 1 & 4 & 1 & 4 & & \\
\hline Total & 5 & 15 & 7 & 5 & 0.140 & 0.046 \\
\hline \multicolumn{7}{|l|}{ 5-12 MONTHS } \\
\hline Oral infections & 5 & 2 & 0 & 2 & & \\
\hline Gastrointestinal infection ${ }^{a}$ & 0 & 1 & 0 & 0 & & \\
\hline Other viral infections & 5 & 4 & 8 & 3 & & \\
\hline Other bacterial infections & 2 & 0 & 0 & 1 & & \\
\hline Hematochezia & 0 & 0 & 0 & 0 & & \\
\hline Constipation & 0 & 0 & 0 & 0 & & \\
\hline Other non-infectious diseases & 0 & 0 & 1 & 2 & & \\
\hline Skin effects & 1 & 0 & 0 & 0 & & \\
\hline Total & 13 & 7 & 9 & 8 & 0.999 & 0.999 \\
\hline
\end{tabular}

BF, breastfed reference group; SF, standard formula; MFGM, formula supplemented with milk fat globule membrane; F19, formula supplemented with Lactobacillus paracasei ssp. paracasei strain F19. ${ }^{a}$ Not diarrhea.

affect iron status during early infancy including maternal iron status, cord clamping (39), and type of feeding (40).

Several randomized double-blind trials have assessed the effects on health of adding MFGM to infant formulas or diets for young children. In Belgian preschool children, a daily chocolate formula-milk supplemented with a phospholipid-rich MFGM concentrate resulted in a significantly reduced number of days with fever during the 4-month intervention period compared to the corresponding unsupplemented formula-milk (41). In a Peruvian double-blind randomized controlled trial healthy, primarily breastfed infants ages 6-11 months were given instant complementary food fortified with $1 \mathrm{RDA}$ of multiple micronutrients, with either an MFGM-enriched protein fraction or skim milk powder (control group) as the protein source, daily for 6 months. The primary outcome was diarrhea. The groups showed no difference in the incidence of diarrhea, although the longitudinal prevalence of diarrhea was significantly lower in the MFGM compared with the control group. In a multivariate model adjusted for initial anemia and potable water facilities, the incidence of bloody diarrhea was lower in the MFGM group (30). In a Swedish study, term infants were randomized before the age of 2 months to formula with slightly reduced protein and energy content and supplemented with the same MFGM preparation or SF $(28,42,43)$. A breastfed group served as reference. The formulas were used until age 6 months, and the infants were followed to age 12 months. During the intervention, the MFGM group had a lower incidence of acute otitis media than the SF group ( $1 \%$ vs. $9 \%, p=0.034)$, lower incidence and longitudinal prevalence of antipyretic use, and a lower concentration of secretory IgG against pneumococci after vaccination (29), in agreement with previous findings of reduced infections.

In contrast, in a multicenter non-inferiority DBRCT on healthy term infants, Billeaud et al. evaluated the safety of two infant formulas, enriched with a lipid-rich or a protein-rich bovine MFGM fraction, respectively. At 14 days of age, the infants were randomized to receive standard infant formula (control), or one of the two experimental formulas until age 4 months. The primary outcome, weight gain, was non-inferior in the MFGM-lipid and MFGM-protein groups compared with the control group. Among secondary and exploratory outcomes, few between-group differences were observed. AEs and morbidity rates were similar across groups except for a higher rate of eczema with protein-rich MFGM compared to the other two groups (44). Of note, however, the total number of infants with eczema was low, and a Swedish study did not have a similar finding (45). A trial in India, evaluating the preventive effect against diarrhea of supplementation with a ganglioside concentrate during the second year of life, was inconclusive in the primary outcome of rotavirus diarrhea, and in secondary outcomes, including all-cause diarrhea (46). However, the study was underpowered because of a lower-than-expected diarrhea incidence. 


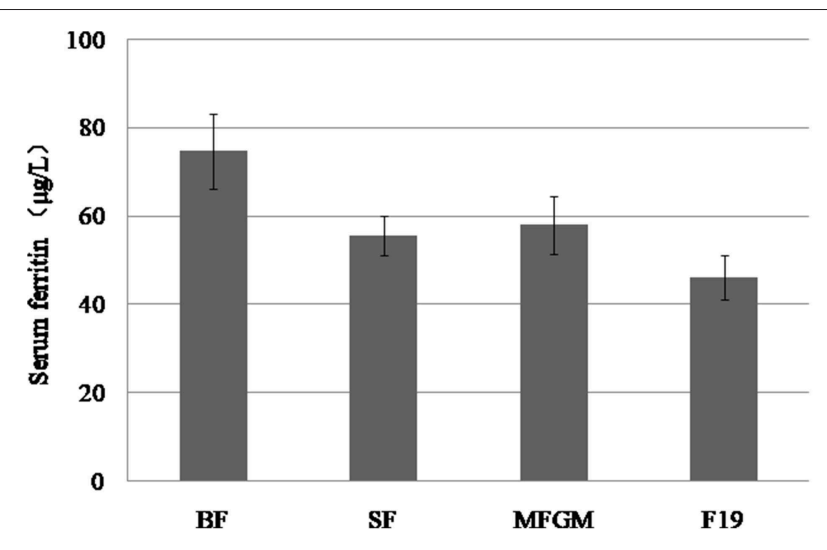

FIGURE 3 | Serum ferritin levels in the breastfed group and in the formula-fed groups. S-ferritin concentration was analyzed in a random sample consisting of 50 infants from each of the four groups. There was no difference in s-ferritin concentration among the formula-fed groups, but the F19 group was

significantly lower than the breastfed group $(p=0.008)$, while there was no difference between the standard formula and MFGM and the breastfed group.

There was a sex difference, with s-ferritin being higher in girls than in boys, a difference that was statistically significant for the breastfed and F19 groups.

Error bars: 95\% confidence intervals.

In our study, compared to the breastfed group, the SF but not the MFGM and F19 infants had significantly more episodes of fever and days with fever during the intervention. Numerically the MFGM and F19 groups also had fewer episodes of fever and days with fever than the SF group, but not significantly. During the intervention, number of episodes of respiratory tract infections did not differ among the formula-fed groups or between these infants overall and the breastfed group; however, F19 infants had more episodes of upper and lower respiratory tract infections compared to the breastfed group. Furthermore, during the intervention, formula-fed infants did not differ among groups for skin affections, vomiting, or unscheduled visits/hospitalizations, although the F19 group used more antibiotics and had more unscheduled visits/hospitalizations than the breastfed group. After the intervention, only the F19 infants used more antibiotics than the breastfed group, while formula-fed groups showed no differences.

Of interest, during the intervention, the MFGM group did not have significantly more episodes of fever or number of days with fever, diarrhea, and use of antibiotics or unscheduled visits/hospitalization during the intervention than the breastfed group. This finding suggests health benefits particularly for this group. However, these positive effects were less obvious after the intervention when the MFGM group had more episodes of diarrhea than the breastfed infants. The incidence of diarrhea during the study period was lower than expected, making the study underpowered compared with the intention of the design. Furthermore, otitis media was not diagnosed because otoscopy check is not a clinical routine, nor was cognitive development assessed in this study. These results support the previous observation that supplementation with MFGM reduces the gap between formula-fed and breastfed infants with regard to infections. Preclinical studies have demonstrated that several proteins in the MFGM inhibit various pathogens, including Escherichia coli, rotavirus, and enterotoxins (25, 47-49). Further studies are needed to clarify the mechanisms behind the antiinfectious properties of MFGM.

Probiotics have been proposed to influence a wide range of health outcomes, presumably by altering the intestinal microbiota and, directly or indirectly, modulating the developing immune system (7). Studies on the probiotic F19 during the weaning period have shown a lower incidence of eczema at age 12 months (19) and increased capacity to raise immune responses to protein antigens (50). Another study, comparing infant formulas containing oligosaccharides with or without F19, showed a lower incidence of lower respiratory tract infections with synbiotics compared to prebiotics (20). In the present study, we found no significant difference in stool frequency, stool consistency (data not shown), or diarrhea episodes between the F19 and SF groups during the intervention. The two groups also did not differ for other primary or secondary outcomes. However, compared to the breastfed group, the F19 infants had more upper and lower respiratory tract episodes, as noted, along with use of antibiotics, and unscheduled visits/hospitalizations during the intervention period and more use of antibiotics after the intervention. Given the previous observation of lower frequency of lower respiratory tract infections in infants given F19 together with prebiotics (20) and less antibiotic use in infants fed F19 (50), the present observations are difficult to explain. However, besides these unexpected findings, overall, we observed no negative effects of adding probiotics (Lactobacillus F19) to infant formula, in agreement with previous studies. Of interest, consumption of probiotics during early infancy and increased infection risk among toddlers has been demonstrated (51), although the evidence is not conclusive.

Strengths of the present study are the large number of infants included and the double-blind randomized controlled design. Both the F19- and MFGM-enriched formulas met the primary safety endpoint with respect to anthropometrics compared to the SF group and also the breastfed reference group. In general, the formulas were well-tolerated with few AEs. The limitations of the study for investigating other outcomes include the number of sites, the absence of otitis media assessment, and the lack of cognitive development screening.

\section{CONCLUSIONS}

Both the MFGM- and F19-supplemented formulas met the primary safety endpoint of weight gain that did not differ from infants assigned to the control formula. In general, the formulas were well-tolerated but showed no obvious positive effects on the health outcomes studied. Of note, however, during the intervention, the outcomes for the MFGM group were close to those of the breastfed group, supporting previous findings showing that supplementing infant formulas with MFGM narrows the gap between breastfed and formula-fed infants with respect to infections. Our findings provide support for further clinical evaluation of MFGM- or F19-enriched infant formulas. 


\section{DATA AVAILABILITY}

All datasets generated for this study are included in the manuscript/supplementary files.

\section{AUTHOR CONTRIBUTIONS}

$\mathrm{XL}, \mathrm{YP}, \mathrm{BL}$, and $\mathrm{OH}$ : conceptualization. $\mathrm{XL}, \mathrm{YP}, \mathrm{ZL}, \mathrm{BL}$, and $\mathrm{OH}$ : principal investigators. HS: statistical analyses. XL, YP, BL, $\mathrm{OH}$, and HS: methodology. XL, YP, OH, and BL: supervision. HS: visualization. $\mathrm{XL}, \mathrm{OH}, \mathrm{HS}$, and $\mathrm{BL}$ : writing, original draft. XL, YP, ZL, BL, AH, HS, BC, and $\mathrm{OH}$ : writing, review and editing.

\section{FUNDING}

The study was financially supported by Arla Foods amba, Arla Innovation Center, Skejby, Denmark, which also provided the

\section{REFERENCES}

1. Schack-Nielsen L, Michaelsen KF. Advances in our understanding of the biology of human milk and its effects on the offspring. $J$ Nutr. (2007)137:503S-10S. doi: 10.1093/jn/137.2.503S

2. Kørvel-Hanquist A,Djurhuus BD,Homøe P. The effect of breastfeeding on childhood otitis media. Curr Allergy Asthma Rep. (2017) 17:45. doi: $10.1007 / \mathrm{s} 11882-017-0712-3$

3. Agostoni C, Braegger C, Decsi T, Kolacek S, Koletzko B, Michaelsen KF, et al. Breast-feeding: a commentary by the ESPGHAN Committee on Nutrition. J Pediatr Gastroenterol Nutr. (2009)49:112-25. doi: 10.1097/MPG.0b013e31819f1e05

4. Ajetunmobi OM, Whyte B, Chalmers J, Tappin DM, Wolfson L, Fleming $\mathrm{M}$, et al. Breastfeeding is associated with reduced childhood hospitalization: evidence from a Scottish Birth Cohort (1997-2009). J Pediatr. (2015) 166:6205. doi: 10.1016/j.jpeds.2014.11.013

5. Hernell O. Human milk vs. cow's milk and the evolution of infant formulas. Nestle Nutr Workshop Ser Pediatr Program. (2011) 67:17-28. doi: $10.1159 / 000325572$

6. Pannaraj PS, Li F, Cerini C, Bender JM, Yang S, Rollie A, et al. Association between breast milk bacterial communities and establishment and development of the infant gut microbiome. JAMA Pediatr. (2017) 171: 647-54. doi: 10.1001/jamapediatrics.2017.0378

7. West CE, Dzidic M, Prescott SL, Jenmalm MC. Bugging allergy; role of pre, pro- and synbiotics in allergy prevention. Allergol Int. (2017) 66: 529-38. doi: 10.1016/j.alit.2017.08.001

8. Cani PD, Everard A. Talking microbes: when gut bacteria interact with diet and host organs. Mol Nutr Food Res. (2016) 60: 58-66. doi: 10.1002/mnfr.201500406

9. Guaraldi F, Salvatori G. Effect of breast and formula feeding on gut microbiota shaping in newborns. Front Cell Infect Microbiol. (2012) 2:94. doi: $10.3389 /$ fcimb. 2012.00094

10. Harmsen HJ, Wildeboer-Veloo AC, Raangs GC, Wagendorp AA, Klijn N, Bindels JG, et al. Analysis of intestinal flora development in breastfed and formula-fed infants by using molecular identification and detection methods. J Pediatr Gastroenterol Nutr. (2000) 30: 61-7. doi: 10.1097/00005176-200001000-00019

11. Groer MW, Luciano AA, Dishaw LJ, Ashmeade TL, Miller E, Gilbert JA. Development of the preterm infant gut microbiome: a research priority. Microbiome. (2014)2:38. doi: 10.1186/2049-2618-2-38

12. Chong CYL, Bloomfield FH, O'Sullivan JM. Factors affecting gastrointestinal microbiome development in neonates. Nutrients. (2018)10:274. doi: $10.3390 /$ nu10030274 experimental and standard formulas, and Arla Foods Ingredients Group P/S, Viby J, Denmark.

\section{ACKNOWLEDGMENTS}

We express our gratitude to the participating infants and their parents. We also want to thank Yinhua Chen and Rong $\mathrm{Li}$ (Children's Hospital of Nanjing Medical University), Xirong Liu and Xiaojing Sheng (the Second Hospital of Nanjing Medical University), Meiling Tong and Yachun Xie (Nanjing Maternity and Child Health Hospital), Zhanhua Yang (Huaian Maternity and Child Health Hospital), Genju Wang (Nanjing Secondary Hospital), Peiru Jiang and Yihong Zhao (Public Health Center of Fudan University), Lin Pang (Bejing Di Tan Hospital), and Zhaoxia Wang (the First Hospital of Jilin University) for recruiting the participants and for excellent contact with infants and parents/caretakers. We thank Zhiying Jiang for help with data entry.

13. Ozen M, Kocabas Sandal G, Dinleyici EC. Probiotics for the prevention of pediatric upper respiratory tract infections: a systematic review. Expert Opin Biol Ther. (2015)15:9-20. doi: 10.1517/14712598.2015.980233

14. Szajewska H, Canani RB, Guarino A, Hojsak I, Indrio F, Kolacek $\mathrm{S}$, et al. Probiotics for the prevention of antibiotic-associated diarrhea in children. J Pediatr Gastroenterol Nutr. (2016) 62:495-506. doi: 10.1097/MPG.0000000000001081

15. Forsberg A, West CE, Prescott SL, Jenmalm MC. Pre- and probiotics for allergy prevention: time to revisit recommendations? Clin Exp Allergy. (2016) 46:1506-21. doi: 10.1111/cea.12838

16. Abrahamsson TR, Jakobsson T, Björksten B, Oldaeus G, Jenmalm MC. No effect of probiotics on respiratory allergies: a seven-year follow-up of a randomized controlled trial in infancy. Pediatr Allergy Immunol. (2013) 24: 556-61. doi: 10.1111/pai.12104

17. Kuitunen M, Kukkonen K, Juntunen-Backman K, Korpela R, Poussa T, Tuure $\mathrm{T}$, et al. Probiotics prevent IgE-associated allergy until age 5 years in cesareandelivered children but not in the total cohort. J Allergy Clin Immunol. (2009) 123: 335-41. doi: 10.1016/j.jaci.2008.11.019

18. Wickens K, Stanley TV, Mitchell EA, Barthow C, Fitzharris P, Purdie G, et al. Early supplementation with Lactobacillus rhamnosus HN001 reduces eczema prevalence to 6 years: does it also reduce atopic sensitization? Clin Exp Allergy. (2013) 43:1048-57. doi: 10.1111/cea.12154

19. West CE, Hammarström ML, Hernell O. Probiotics during weaning reduce the incidence of eczema. Pediatr Allergy Immunol. (2009) 20:430-7. doi: 10.1111/j.1399-3038.2009.00745.x

20. Szajewska H, Ruszczynski M, Szymanski H, Sadowska-Krawczenko I, Piwowarczyk A, Rasmussen PB, et al. Effects of infant formula supplemented with prebiotics compared with synbiotics on growth up to the age of 12 mo: a randomized controlled trial. Pediatr Res. (2017) 81:752-8. doi: $10.1038 /$ pr.2017.5

21. Hernell O, Timby N, Domellöf M, Lönnerdal B. Clinical benefits of milk fat globule membranes for infants and children. J Pediatr. (2016) 173:S60-5. doi: 10.1016/j.jpeds.2016.02.077

22. Lee H PE, Hasegawa Y, Larke J, Parenti M, Wang A, Hernell O, et al. Compositional dynamics of the milk fat globule and its role in infant development. Front Pediatr. (2018) 6:313-32. doi: 10.3389/fped.2018.00313

23. Rueda $\mathrm{R}$. The role of dietary gangliosides on immunity and the prevention of infection. Br J Nutr. (2007) 98:S68-73. doi: 10.1017/S0007114507832946

24. Triantis V, Bode L, van Neerven RJJ. Immunological effects of human milk oligosaccharides. Front Pediatr. (2018) 6:190. doi: 10.3389/fped.2018.00190

25. Spitsberg VL. Invited review: bovine milk fat globule membrane as a potential nutraceutical. J Dairy Sci. (2005) 88:2289-94. doi: 10.3168/jds.S0022-0302(05)72906-4 
26. Liao Y, Alvarado R, Phinney B, Lönnerdal B. Proteomic characterization of human milk fat globule membrane proteins during a 12 month lactation period. J Proteome Res. (2011) 10:3530-41. doi: 10.1021/pr200149t

27. Gurnida DA, Rowan AM, Idjradinata P, Muchtadi D, Sekarwana N. Association of complex lipids containing gangliosides with cognitive development of 6-month-old infants. Early Hum Dev. (2012) 88:595-601. doi: 10.1016/j.earlhumdev.2012.01.003

28. Timby N, Domellöf E, Hernell O, Lönnerdal B, Domellöf $M$. Neurodevelopment, nutrition, and growth until 12 mo of age in infants fed a low-energy, low-protein formula supplemented with bovine milk fat globule membranes: a randomized controlled trial. Am J Clin Nutr. (2014) 99: 860-8. doi: 10.3945/ajcn.113.064295

29. Timby N, Hernell O, Vaarala O, Melin M, Lönnerdal B, Domellöf M. Infections in infants fed formula supplemented with bovine milk fat globule membranes. J Pediatr Gastroenterol Nutr. (2015)60: 384-9. doi: 10.1097/MPG.0000000000000624

30. Zavaleta N, Kvistgaard AS, Graverholt G, Respicio G, Guija H, Valencia N, et al. Efficacy of an MFGM-enriched complementary food in diarrhea, anemia, and micronutrient status in infants. J Pediatr Gastroenterol Nutr. (2011) 53:561-568. doi: 10.1097/MPG.0b013e318225cdaf

31. WHO. WHO Child Growth Standards: Length/Height-For-Age, Weight-ForAge, Weight-For-Length, Weight-For-Height and Body Mass Index-For-Age: Methods And Development. Geneva: World Health Organization (2006).

32. Crielaard W, Zaura E, Schuller AA, Huse SM, Montijn RC, Keijser BJ. Exploring the oral microbiota of children at various developmental stages of their dentition in the relation to their oral health. BMC Med Genomics. (2011) 4:22. doi: 10.1186/1755-8794-4-22

33. Sieuwerts S, Håkansson J. Development of a standardized method for the quantification of Lactobacillus paracasei F19 In stool samples of various ages. EC Nutr. (2016) 3.3:633-42.

34. Koletzko B, Aggett PJ, Bindels JG, Bung P, Ferre P, Gil A, et al. Growth, development and differentiation: a functional food science approach. $\mathrm{Br} J$ Nutr. (1998) 80:41. doi: 10.1079/BJN19980104

35. Vendt N, Grunberg H, Tuure T, Malminiemi O, Wuolijoki E, Tillmann V, et al. Growth during the first 6 months of life in infants using formula enriched with Lactobacillus rhamnosus GG: double-blind, randomized trial. J Hum Nutr Diet. (2006)19:51-8. doi: 10.1111/j.1365-277X.2006.00660.x

36. Agostoni C, Grandi F, Giannì ML, Silano M, Torcoletti M, Giovannini M. Growth patterns of breast fed and formula fed infants in the first 12 months of life: An Italian study. Arch Dis Child. (1999) 81:395-9. doi: 10.1136/adc.81.5.395

37. Karlsson Videhult F, Öhlund I, Stenlund H, Hernell O, West CE. Probiotics during weaning: a follow-up study on effects on body composition and metabolic markers at school age. Eur J Nutr. (2015) 54:355-63. doi: 10.1007/s00394-014-0715-y

38. Lönnerdal B. Bioactive proteins in human milk-potential benefits for preterm infants. Clin Perinatol. (2017) 44:179-91. doi: 10.1016/j.clp.2016.11.013

39. Chaparro CM, Neufeld LM, Tena Alavez G, Eguia-Líz Cedillo R, Dewey KG. Effect of timing of umbilical cord clamping on iron status in Mexican infants: a randomised controlled trial. Lancet. (2006) 367:1997-2004. doi: 10.1016/S0140-6736(06)68889-2

40. Domellöf M, Braegger C, Campoy C, Colomb V, Decsi T, Fewtrell M, et al. Iron requirements of infants and toddlers. J Pediatr Gastroenterol Nutr. (2014) 58:119-29. doi: 10.1097/MPG.0000000000000206

41. Veereman-Wauters G, Staelens S, Rombaut R, Dewettinck K, Deboutte D, Brummer RJ, et al. Milk fat globule membrane (INPULSE) enriched formula milk decreases febrile episodes and may improve behavioral regulation in young children. Nutrition. (2012) 28:749-52. doi: 10.1016/j.nut.2011.10.011

42. Timby N, Lönnerdal B, Hernell O, Domellöf M. Cardiovascular risk markers until 12 mo of age in infants fed a formula supplemented with bovine milk fat globule membranes. Pediatr Res. (2014) 76: 394-400. doi: 10.1038/pr.20 14.110

43. Timby N, Domellöf M, Lönnerdal B, Hernell O. Comment on "Safety and tolerance evaluation of milk fat globule membrane-enriched infant formulas: arandomized controlled multicenter non-inferiority trial in healthy term infants". Clin Med Insights Pediatr. (2015) 9:63-4. doi: 10.4137/CMPed.S27185

44. Billeaud C, Puccio G, Saliba E, Guillois B, Vaysse C, Pecquet S, et al. Safety and tolerance evaluation of milk fat globule membrane-enriched infant formulas: a randomized controlled multicenter non-inferiority trial in healthy term infants. Clin Med Insights Pediatr. (2014) 8:51-60. doi: 10.4137/CMPed.S16962

45. Timby N, Domellöf M, Lönnerdal B, Hernell O. Supplementation of infant formula with bovine milk fat globule membranes. Adv Nutr. (2017) 8:351-5. doi: 10.3945/an.116.014142

46. Poppitt SD MR, Wiessing KR, Goyal VK,Chitkara AJ,Gupta S, et al. Bovine complex milk containing gangliosides for precvention of rotavirus infection and diarrhea in northern Indian infants. J Pediatr Gastroenterol Nutr. (2014) 59:167-71. doi: 10.1097/MPG.0000000000000398

47. Lönnerdal B. Infant formula and infant nutrition: bioactive proteins of human milk and implications for composition of infant formulas. Am J Clin Nutr. (2014) 99:712S-7S. doi: 10.3945/ajcn.113.071993

48. Yolken RH, Peterson JA, Vonderfecht SL, Fouts ET, Midthun K, Newburg DS. Human milk mucin inhibits rotavirus replication and prevents experimental gastroenteritis. J Clin Invest. (1992) 90:1984-91. doi: 10.1172/JCI116078

49. Laegreid A, Otnaess AB, Fuglesang J. Human and bovine milk: comparison of ganglioside composition and enterotoxin-inhibitory activity. Pediatr Res. (1986) 20: 416-21. doi: 10.1203/00006450-198605000-00008

50. West CE, Gothefors L, Granström M, Käyhty H, Hammarström M-L, Hernell O. Effects of feeding probiotics during weaning on infections and antibody responses to diphteria, tetanus and Hib vaccines. Pediatr Allergy Immunol. (2008) 19:53-60. doi: 10.1111/j.1399-3038.2007.00583.x

51. Quin C, Estaki M, Vollman DM, Barnett JA, Gill SK, Gibson DL. Probiotic supplementation and associated infant gut microbiome and health: a cautionary retrospective clinical comparison. Sci Rep. (2018) 8:8283. doi: 10.1038/s41598-01826423-3

Conflict of Interest Statement: The study was financially supported by Arla Foods amba, Arla Innovation Center, Skejby, Denmark and Arla Foods Ingredients, Viby, Denmark. Arla Foods amba provided the experimental and standard formulas. $\mathrm{BC}$ is an employee of Arla Foods amba and AH is an employee at Arla Foods Ingredients. $\mathrm{XL}, \mathrm{YP}, \mathrm{ZL}, \mathrm{HS}, \mathrm{BL}$, and $\mathrm{OH}$ have received honoraria and/or travel grants or research grants from Arla Foods.

Copyright (c) 2019 Li, Peng, Li, Christensen, Heckmann, Stenlund, Lönnerdal and Hernell. This is an open-access article distributed under the terms of the Creative Commons Attribution License (CC BY). The use, distribution or reproduction in other forums is permitted, provided the original author(s) and the copyright owner(s) are credited and that the original publication in this journal is cited, in accordance with accepted academic practice. No use, distribution or reproduction is permitted which does not comply with these terms. 